\title{
Activity-Trip Chaining Behavior of Urban Low-Income Populations in Nanjing, China: A Structural Equations Analysis
}

\author{
Zhaoming Chu, ${ }^{1}$ Hui Chen, ${ }^{2}$ Lin Cheng, ${ }^{1}$ Xuewu Chen, ${ }^{1}$ and Senlai Zhu ${ }^{1}$ \\ ${ }^{1}$ School of Transportation, Southeast University, Nanjing 210096, China \\ ${ }^{2}$ Chengxian College, Southeast University, Nanjing 210088, China \\ Correspondence should be addressed to Zhaoming Chu; chuzhaoming@126.com
}

Received 31 October 2013; Revised 22 March 2014; Accepted 27 March 2014; Published 22 April 2014

Academic Editor: Huimin Niu

Copyright (c) 2014 Zhaoming Chu et al. This is an open access article distributed under the Creative Commons Attribution License, which permits unrestricted use, distribution, and reproduction in any medium, provided the original work is properly cited.

\begin{abstract}
This paper analyzes the activity-trip chaining behavior of urban low-income populations in Nanjing, China, based on a specific travel survey of low-income residents of Nanjing city (2010), and the database of residents travel survey of Nanjing city (2009). Individual's information of activity participation and trip chains is extracted from the daily travel diary and matched with individual and household characteristics. On top of correlation analysis and normalization process, using the software AMOS, two structural equation models are formulated to analyze the relationship among individuals' sociodemographics, activity duration, and trip chains of low-income populations and non-low-income populations, respectively. Seven household characteristics and six individual characteristics are chosen as the exogenous variables, while 4 indices of activity duration and 4 indices of trip chains are sleeted as the endogenous variables. The result shows that the activity-travel behavior of urban low-income populations is quite unique, which offers promising insights into activity-trip chaining behavior of the poor and extends the need to crafting effective transportation policies specifically for urban low-income populations in developing countries.
\end{abstract}

\section{Introduction}

Because of the fast urbanization in developing countries, large amount of peasants swarm to the urban area and work there. These peasant-workers together with unemployed city residents consist the main parts of urban low-income populations in developing countries. However, in recent years, the soaring house price in big cities forces urban lowincome populations move to the urban fringe in developing countries; meanwhile, transportation becomes a big problem to these low-income residents. How to satisfy the travel demand of urban low-income residents and how to provide cheap and convenient service for them are urgent problems to be solved. The research on travel behavior of low-income residents can help to promote social fairness and justice, ease the social conflicts, and build a harmonious society.

To solve the various transportation problems encountered by the urban low-income populations in developing countries, it is required to capture the characteristics of their activity-travel behavior first. An activity-based survey method was selected because it typically yields higher rates of trip recall than other methods and is therefore relatively well suited to investigate travel behavior in its fuller complexity. As an extremely flexible linear-in-parameters multivariate statistical modeling technique, structural equation modeling (SEM) has been proved to have considerable potential in modeling activity-based travel demand modeling.

The primary intention of this paper is to explore the characteristics of activity-trip chaining behavior of urbanlow-income populations in developing countries. Specifically, we use the structural equations to analyze the correlation of sociodemographic, activity participation, and trip chaining behavior of urban low-income populations and capture the most critical factors that influence the travel behavior of the poor by comparing the urban low income populations and non-low-income populations. Our findings are expected to further add to the rich body of knowledge on activitybased travel demand modeling by focusing on urban lowincome populations, meanwhile providing useful information for crafting effective policies to guarantee the cheap and convenient travel of the poor. 
The organization of the paper is as follows. In the following section, we briefly review the relevant literature on the topic of this study. In Section 3, we introduce the principle of structural equation modeling. Section 4 describes the data used in this paper. Section 5 presents the development and calibration of the models. Section 6 presents selected findings of model estimation results. Finally, the paper ends with conclusions and future research directions.

\section{Literature Review}

In the literature, travel behavior of urban low-income residents has not been studied much due to the limited data. Several representative studies are listed as follows.

Giuliano et al. examined the use of public transit by lowincome households and they declared that public transit is not a reasonable substitute for the private vehicle for most people, poor or not poor $[1,2]$. Blumenberg and Haas claimed that welfare recipients with unlimited access to automobiles have higher employment rates and report fewer transportation problems [3]. Clifton presented a few of the challenges facing those interested in the intersection between poverty and travel behavior and introduced opportunities to explore lowincome travel using some new approaches [4]. McDonald et al. found that the free-bus pass program increased lowincome students' bus ridership and after-school participation; they also found that the increases in bus use were greater among free-bus pass holders, in areas with high levels of bus service and among high school students [5].

The above studies are all based on the data of developed countries. Recently, some researches started to focus on the low-income populations in developing countries. Using an activity diary survey administered in Cape Town, a city of South Africa, Behrens found that travel occurring by nonmotorized modes, for non-work purposes and during off-peak periods, is considerable. They also argued that restricting the focus of analysis to motorized, work, and peak period tripmaking can create serious misconceptions of the true nature of travel behavior, particularly of low-income households [6]. Srinivasan and Rogers surveyed 70 households which were located in two different parts of Chennai (a city of India). The results indicated that residents in the centrally located settlement were more likely to use nonmotorized travel modes than the peripherally located residents [7].

More recently, researchers paid more attention to the mobility of low-income populations. Thakuriah et al. proposed an index of perceived service importance (PSI) to evaluate low-income transit services [8]. Taylor et al. focused on the role of the car of the travel choices and needs of lowincome households and they concluded that the car clearly plays an important role in the lives of low-income households [9]. Gao and Johnston examined possible impacts of car ownership promotion versus transit improvements on job accessibility, work trips, and traveler benefits, for low-income households [10].

However, most of the travel behavior studies pertaining to low-income populations are trip-based and ignored the effects of activity participation on travel behavior. None of these studies have examined trip chaining behavior of the poor.

After 30 years of development, activity-based travel demand modeling has been widely used in travel behavior analysis, but there are few activity-based travel demand models specifically for low-income populations. Meanwhile, due to the availability of improved software, structural equation modeling (SEM) has become an effective tool to model travel behavior, especially in the field of activity-based travel demand modeling [11].

Kitamura et al. was the first to apply SEM in modeling joint demand for activity duration and travel. Based on the California time use survey data, they confirmed a negative feedback of commute time to non-work activities [12]. Lu and Pas described the development, estimation, and interpretation of a model relating sociodemographics, activity participation, and travel behavior. Using the structural equation modeling methodology with the endogenous variables of travel behavior indices, a complex set of interrelationships among the variables of interest is estimated simultaneously. They found that travel behavior can be better explained by including activity participation endogenously in the model than through sociodemographics alone [13]. Golob estimated a joint model of work and non-work activity duration, four types of trip chains, and three measures of travel time expenditure. In this model, maximum likelihood (ML) estimation was applied to Portland data, and the effects of in-home work and residential accessibility were also explored [14].

More recently, using activity-based travel survey data collected in the Washington, DC metropolitan area, Kuppam and Pendyala carried out an exploratory analysis of commuters' activity and travel patterns to investigate and estimate relationships among sociodemographics, activity participation, and travel behavior. The model estimation results show that significant trade-offs exist between in-home and out-of-home activity participation [15]. Chung and Ahn used structural equation models to analyze the day-to-day activity participation and travel behavior in a developing country. They confirmed that activity patterns are significantly different on weekdays and weekends. Furthermore, they found that during weekdays there are some day-to-day variations in the patterns of activity participation and travel behavior [16].

Due to the modern and hectic life style, travel behavior of people is becoming complex day by day, especially in fast developing countries. Therefore, the better understanding of trip chain decision making is necessary to transportation researchers and policy makers. In the last few years, researchers began to study the trip-chaining behavior in developing countries [17, 18]. However, to the best of our knowledge, there is still no research specifically for the lowincome populations in developing countries, who are the main focuses of this study.

To sum up, previous studies have confirmed that activity participation had a significant relationship with travel behavior, particularly in time use. However, less work has been done to explore the impact of activity participation on trip chaining specifically for low-income populations. Since previous studies have primarily focused on households in developed 
courtiers, there is a great need to formulate relationships of sociodemographics, activity participation, and trip chaining of urban low-income populations in developing countries, such as China.

\section{Methodology}

In order to estimate a simultaneous model of the interrelationship among sociodemographics, activity duration, and trip chaining behavior of urban low-income residents, we applied the methodology of structural equation model (SEM). In addition, we are also interested in the direct and indirect effects of one variable on another, which can be provided by the estimation result of structure equation model.

Since all variables used in this research are observed variables, structural equation models without latent variables are therefore reduced to the following form:

$$
\mathbf{y}=\mathbf{B y}+\Gamma \mathbf{x}+\zeta,
$$

where $\mathbf{y}$ is a column vector of $p$ endogenous variables, $\mathbf{x}$ is a column vector of $q$ exogenous variables, $\mathbf{B}$ is a matrix ( $p \times p)$ of direct effects between pairs of $p$ endogenous variables, $\Gamma$ is a matrix $(p \times q)$ of regression effects associated with exogenous variables, and $\zeta$ is a column vector of the error terms, with the standard assumption that $\zeta$ is uncorrelated with $\mathbf{x}$. Further, we denote $\boldsymbol{\Phi}$ by the covariance matrix of $\mathbf{x}$ and $\boldsymbol{\Psi}$ by the covariance matrix of $\zeta$.

Structural equations systems are estimated by covariancebased structural analysis, in which the difference between the sample covariance and the model implied covariance matrices is minimized. The fundamental hypothesis for the covariance-based estimation procedures is that the covariance matrix of the observed variable is a function of a set of parameters as shown in the following equation: $\boldsymbol{\Sigma}=\boldsymbol{\Sigma}(\boldsymbol{\theta})$, where $\Sigma$ is the population covariance matrix of observed variables, $\boldsymbol{\theta}$ is a vector that contains the model parameters, and $\boldsymbol{\Sigma}(\boldsymbol{\theta})$ is the covariance matrix written as a function of $\boldsymbol{\theta}$.

The matrix $\boldsymbol{\Sigma}(\boldsymbol{\theta})$ has three components, namely, the covariance matrix of $\mathbf{y}$, the covariance matrix of $\mathbf{x}$ with $\mathbf{y}$, and the covariance matrix of $\mathbf{x}$. Then, it can be shown that

$$
\begin{aligned}
\boldsymbol{\Sigma}(\boldsymbol{\theta}) & =\left[\begin{array}{cc}
\Sigma_{\mathrm{yy}}(\boldsymbol{\theta}) & \Sigma_{\mathrm{yx}}(\boldsymbol{\theta}) \\
\Sigma_{\mathrm{xy}}(\boldsymbol{\theta}) & \Sigma_{\mathrm{xx}}(\boldsymbol{\theta})
\end{array}\right] \\
& =\left[\begin{array}{cc}
(\mathbf{I}-\mathbf{B})^{-1}\left(\boldsymbol{\Gamma} \Phi \boldsymbol{\Gamma}^{\prime}+\Psi\right)(\mathbf{I}-\mathbf{B})^{-1^{\prime}} & (\mathbf{I}-\mathbf{B})^{-1} \boldsymbol{\Gamma} \boldsymbol{\Phi} \\
\boldsymbol{\Phi} \boldsymbol{\Gamma}^{\prime}(\mathbf{I}-\mathbf{B})^{-1^{\prime}} & \boldsymbol{\Phi}
\end{array}\right] .
\end{aligned}
$$

The unknown parameters in $\mathbf{B}, \Gamma, \boldsymbol{\Phi}$, and $\boldsymbol{\Psi}$ are estimated so that the implied covariance matrix $\boldsymbol{\Sigma}$ is as close as possible to the sample covariance matrix $\mathbf{S}$. In order to achieve this, a fitting function $\mathbf{F}(\mathbf{S}, \boldsymbol{\Sigma}(\boldsymbol{\theta}))$, which is to be minimized, is defined. The fitting function has the properties of being scalar, greater than or equal to zero if and only if $\boldsymbol{\Sigma}(\boldsymbol{\theta})=\mathbf{S}$, and continuous in $\mathbf{S}$ and $\boldsymbol{\Sigma}(\boldsymbol{\theta})$ [19].

Several methods can be used to estimate the parameter in structural equation model, including: maximum likelihood (ML), unweighted least squares (ULS), generalized least squares (GLS), and diagonally weighted least squares (DWLS). In this paper, we primarily used the ML estimation approach.

\section{Data Description}

The city selected for this study is Nanjing, the capital of Jiangsu Province, China. With a total land area of 6,589 square kilometers and an urban population of over eight million (2013), Nanjing is the second largest commercial center in East China after Shanghai.

There are two sources of data; the group of low-income population is from a specific travel survey of low-income residents of Nanjing City (2010) and the group of nonlow-income is from the database of residents travel survey of Nanjing City (2009). In both surveys, all respondents were asked to record their activity and travel information within one weekday on a travel diary. In addition to the activity and travel information, each respondent is required to report the usual set of his/her household and personal sociodemographics.

In the specific survey of low-income populations (2010), 1000 questionnaires were delivered to low-income people residing in three parts of Nanjing City, including shanty areas in inner-city (300 copies), welfare-oriented public housing neighborhoods in the edge area of inner-city (200 copies), and the economically affordable housing neighborhoods in urban fringe (500 copies). Then, totally 904 questionnaires returned from all the surveyed areas.

The non-low-income group consists of residents whose annual per-capita income is higher than the minimum salary threshold of Nanjing City. Thus, 8666 non-low-income residents are selected from the database of residents travel survey of Nanjing City (2009). After eliminating missing data and performing logic checking, we selected 846 individuals in the low-income group and 7534 individuals in the non-lowincome group.

Based on previous research and single factor analysis of sociodemographic attributes and endogenous variables, 7 household attributes and 6 individual attributes are selected as the exogenous variables, while the indices of activity participation and trip chains are selected as the endogenous variables. In particular, the descriptors of activity participation are defined by the duration of four types of activity: in-home, subsistence, maintenance, and leisure. The trip chaining characteristics are defined by descriptors of 4 items, namely, number of work chains, travel time of work chains, number of non-work chains, and travel time of non-work chains (see Table 1).

Statistical characteristics of exogenous variables are shown in Tables 2 and 3. It can be found that $67.5 \%$ of lowincome residents live in the urban fringe, while $60.1 \%$ of the non-low-income residents live in main urban area. Annual household income of low-income populations mainly concentrates on low groups of 10,000 20,000, and 20,000 $50,000 \mathrm{RMB}$, which take up $32.6 \%$ and $45.0 \%$, respectively. In contrast, their non-low-income counterparts concentrate on middle-to-high groups of 20,000 50,000 and 50,000 
TABLE 1: Endogenous variables and exogenous variables.

\begin{tabular}{|c|c|c|c|c|}
\hline & & Variable & Label & Notes \\
\hline \multirow{13}{*}{ Exogenous variables } & \multirow{7}{*}{ Household characteristics } & Residential location & Big_zone & Main urban area $=1$, urban fringe $=2$ \\
\hline & & Number of family members & N_people & \\
\hline & & Number of preschool children & $N \_$kid & \\
\hline & & Annual household income & Income & \\
\hline & & Number of vehicles & $N_{-}$car & \\
\hline & & Number of bikes & N_bike & \\
\hline & & Number of electric bicycles & N_ebike & \\
\hline & \multirow{6}{*}{ Individual characteristics } & Gender & Sex & Male $=1$, female $=2$ \\
\hline & & Job & Job & 9 categories \\
\hline & & Transit IC card holding & IC & Hold a bus IC card $=1$, other $=0$ \\
\hline & & Age & Age & 8 categories \\
\hline & & Driving license holding & Lic & Hold a driver's license $=1$, other $=0$ \\
\hline & & Educational level & Edu & 4 categories \\
\hline \multirow{8}{*}{ Endogenous variables } & \multirow{4}{*}{ Activity duration } & In-home activity & $\mathrm{DH}$ & Sleeping, dinner, housework, and so forth \\
\hline & & Subsistence & $D \_S$ & Work, work-related and school \\
\hline & & Maintenance & $D \_M$ & Obligations, and so forth \\
\hline & & Leisure & $D \_L$ & Amusement, exercise, relaxation, and so forth \\
\hline & \multirow{4}{*}{ Trip chaining } & Number of work chains & N_W & Number of work related chains per day \\
\hline & & Travel time of work chains & $T \_W$ & Travel time of work chains per day \\
\hline & & Number of non-work chains & N_O & Number of non-work chains per day \\
\hline & & Travel time of non-work chains & T_O & Travel time of non-work chains per day \\
\hline
\end{tabular}

TABLE 2: Statistical characteristics of household characteristics.

\begin{tabular}{|c|c|c|c|c|c|c|c|}
\hline \multicolumn{2}{|r|}{ Variable } & \multicolumn{3}{|c|}{ Low-income group } & \multicolumn{3}{|c|}{ Non-low-income group } \\
\hline & & Cases & Valid percent & Cumulative percent & Cases & Valid percent & Cumulative percent \\
\hline \multirow{2}{*}{ Big_Zone } & Inner city & 275 & 32.5 & 32.5 & 4526 & 60.1 & 60.1 \\
\hline & Urban fringe & 571 & 67.5 & 100.0 & 3008 & 39.9 & 100.0 \\
\hline \multirow{4}{*}{$N_{\text {_people }}$} & 1 & 15 & 1.8 & 1.8 & 39 & 0.5 & 0.5 \\
\hline & 2 & 104 & 12.3 & 14.1 & 1489 & 19.8 & 20.3 \\
\hline & 3 & 444 & 52.5 & 66.5 & 5076 & 67.4 & 87.7 \\
\hline & $\geq 4$ & 283 & 33.4 & 100.0 & 921 & 12.3 & 100.0 \\
\hline \multirow{3}{*}{$N \_$Kid } & 0 & 632 & 74.7 & 74.7 & 6613 & 87.8 & 87.8 \\
\hline & 1 & 200 & 23.6 & 98.3 & 892 & 11.8 & 99.6 \\
\hline & $\geq 2$ & 14 & 1.7 & 100.0 & 29 & 0.4 & 100.0 \\
\hline \multirow{5}{*}{ Income } & $<¥ 10,000$ & 38 & 4.5 & 4.5 & 0 & 0 & 0 \\
\hline & $¥ 10,000 \sim ¥ 20,000$ & 276 & 32.6 & 37.1 & 0 & 0 & 0 \\
\hline & $¥ 20,000 \sim ¥ 50,000$ & 381 & 45 & 82.2 & 3962 & 52.6 & 52.6 \\
\hline & $¥ 50,000 \sim ¥ 100,000$ & 151 & 17.8 & 100.0 & 2605 & 34.6 & 87.2 \\
\hline & $>¥ 100,000$ & 0 & 0 & 100.0 & 967 & 12.8 & 100.0 \\
\hline \multirow{3}{*}{ N_Car } & 0 & 692 & 81.8 & 81.8 & 5790 & 76.9 & 76.9 \\
\hline & 1 & 150 & 17.7 & 99.5 & 1640 & 21.8 & 98.6 \\
\hline & $\geq 2$ & 4 & 0.5 & 100.0 & 104 & 1.4 & 100.0 \\
\hline \multirow{4}{*}{ N_bike } & 0 & 225 & 26.6 & 26.6 & 1654 & 22.0 & 22 \\
\hline & 1 & 507 & 59.9 & 86.5 & 3315 & 44.0 & 66.0 \\
\hline & 2 & 104 & 12.3 & 98.8 & 1988 & 26.4 & 92.3 \\
\hline & $\geq 3$ & 10 & 1.2 & 100.0 & 577 & 7.7 & 100.0 \\
\hline \multirow{4}{*}{$N \_$_ebike } & 0 & 343 & 40.5 & 40.5 & 3330 & 44.2 & 44.2 \\
\hline & 1 & 347 & 41 & 81.6 & 3314 & 44 & 88.2 \\
\hline & 2 & 140 & 16.5 & 98.1 & 833 & 11.1 & 99.2 \\
\hline & $\geq 3$ & 16 & 1.9 & 100.0 & 57 & 0.8 & 100.0 \\
\hline
\end{tabular}


TABLE 3: Statistical characteristics of individual characteristics.

\begin{tabular}{|c|c|c|c|c|c|c|c|}
\hline \multirow{2}{*}{\multicolumn{2}{|c|}{ Variable }} & \multicolumn{3}{|c|}{ Low-income group } & \multicolumn{3}{|c|}{ Non-low-income group } \\
\hline & & Cases & Valid percent & Cumulative percent & cases & Valid percent & Cumulative percent \\
\hline \multirow{2}{*}{ Gender } & Male & 416 & 49.2 & 49.2 & 1 & 49.7 & 49.7 \\
\hline & Female & 430 & 50.8 & 100 & 2 & 50.3 & 100.0 \\
\hline \multirow{9}{*}{ Job } & School children & 73 & 8.6 & 8.6 & 1 & 11.3 & 11.3 \\
\hline & College student & 15 & 1.8 & 10.4 & 2 & 2.6 & 13.9 \\
\hline & Factory worker & 124 & 14.7 & 25.1 & 3 & 15.0 & 28.8 \\
\hline & Service staff & 114 & 13.5 & 38.5 & 4 & 8.9 & 37.7 \\
\hline & Civil servant & 79 & 9.3 & 47.9 & 5 & 25.8 & 63.5 \\
\hline & Self-employed & 43 & 5.1 & 53.0 & 6 & 5.8 & 69.3 \\
\hline & Retired & 246 & 29.1 & 82.0 & 7 & 17.7 & 87.0 \\
\hline & Peasant & 51 & 6.0 & 88.1 & 8 & 1.3 & 88.3 \\
\hline & Others & 101 & 11.9 & 100.0 & 9 & 11.7 & 100.0 \\
\hline \multirow{2}{*}{ Transit IC Card } & Yes & 722 & 85.3 & 85.3 & 1 & 63.9 & 63.9 \\
\hline & No & 124 & 14.7 & 14.7 & 2 & 36.1 & 100.0 \\
\hline \multirow{8}{*}{ Age } & $6 \sim 14$ & 43 & 5.1 & 5.1 & 1 & 6.6 & 6.6 \\
\hline & $15 \sim 19$ & 30 & 3.5 & 8.6 & 2 & 5.1 & 11.7 \\
\hline & $20 \sim 24$ & 75 & 8.9 & 17.5 & 3 & 5.6 & 17.2 \\
\hline & $25 \sim 29$ & 115 & 13.6 & 31.1 & 4 & 8.8 & 26.1 \\
\hline & $30 \sim 39$ & 127 & 15.0 & 46.1 & 5 & 19.4 & 45.5 \\
\hline & $40 \sim 49$ & 110 & 13.0 & 59.1 & 6 & 24.3 & 69.8 \\
\hline & $50 \sim 59$ & 148 & 17.5 & 76.6 & 7 & 18.6 & 88.4 \\
\hline & $\geq 60$ & 198 & 23.4 & 100 & 8 & 11.6 & 100.0 \\
\hline \multirow{2}{*}{ Driving license } & Yes & 118 & 13.9 & 13.9 & 1 & 27.6 & 27.6 \\
\hline & No & 728 & 86.1 & 100.0 & 2 & 72.4 & 100.0 \\
\hline \multirow{4}{*}{ Educational level } & Middle school & 429 & 50.7 & 50.7 & 1 & 26.5 & 26.5 \\
\hline & High School & 323 & 38.2 & 88.9 & 2 & 38.5 & 64.8 \\
\hline & Undergraduate & 94 & 11.1 & 100.0 & 3 & 33.9 & 98.7 \\
\hline & Graduate & & & & 4 & 1.3 & 100.0 \\
\hline
\end{tabular}

100,000 RMB. Note that, $18.2 \%$ of low-income household own at least one car and $13.9 \%$ of the low-income individuals hold a driving license, which indicates that automobile begin to enter the Chinese urban families, even the not so affluent ones.

Table 4 shows statistical characteristics of the 8 endogenous variables that consist of descriptors of activity and trip chaining. Note that, on average, the duration of out-of-home activities are less in the low-income group than that of the non-low-income group. The number of trip chains indicates that low-income populations generally do less out-of-home activities.

\section{Model Specification}

On the basis of activity-based travel demand theory and previous researches on SEMs, a possible structural equation modeling framework was laid out as shown in Figure 1, which captures the interrelationships among sociodemographics, activity participation, and trip chaining simultaneously.

There are three basic assumptions in the initial SEM models. First, sociodemographics characteristics affect both the activity participation and travel behavior of travelers. Second, the increase of in-home activity participation will reduce

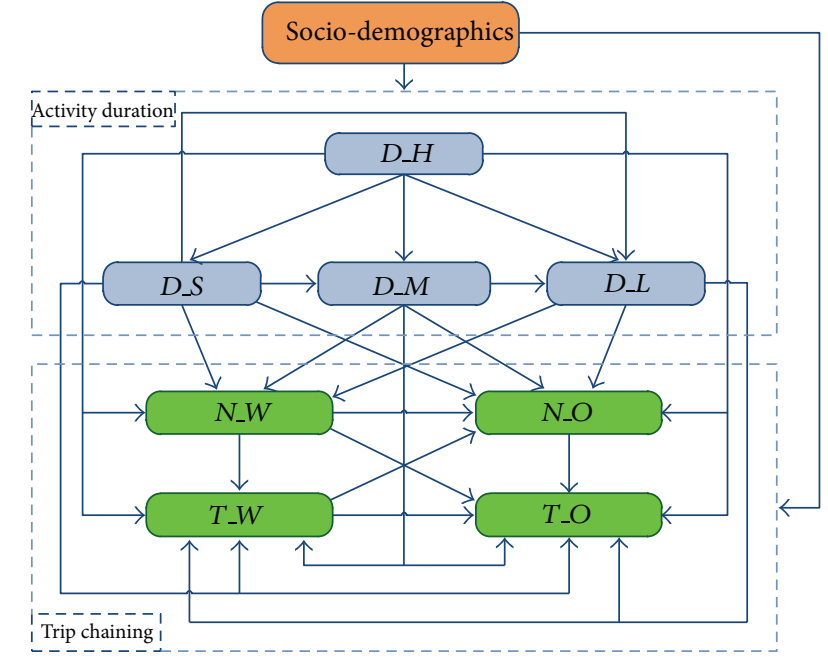

FIGURE 1: Causal structure linking the exogenous variables and endogenous variables.

the time spent on out-of-home activities, the three types of out-of-home activities affect each other mutually. Third, 
TABLE 4: Statistical characteristics of the endogenous variables.

\begin{tabular}{lcccccccccc}
\hline \multirow{2}{*}{ Endogenous variables } & \multicolumn{3}{c}{ Low-income group (846 individuals) } & \multicolumn{3}{c}{ Non-low-income group (7534 individuals) } \\
& $\begin{array}{c}\text { Population } \\
\text { Mean }\end{array}$ & Variance & Mean & Variance & Sample size & Mean & Variance & Mean & Variance & Sample size \\
\hline D_H (hour) & 16.93 & 4.03 & 16.93 & 4.03 & 846 & 15.36 & 3.42 & 15.34 & 3.42 & 7534 \\
D_S (hour) & 5.11 & 4.59 & 8.86 & 1.81 & 488 & 6.36 & 4.19 & 8.67 & 1.97 & 5531 \\
D_M (hour) & 0.31 & 0.76 & 1.17 & 1.02 & 225 & 0.36 & 0.97 & 1.25 & 1.48 & 2164 \\
D_L (hour) & 0.62 & 1.37 & 2.18 & 1.80 & 238 & 0.65 & 1.60 & 2.55 & 2.28 & 1906 \\
N_W (chain) & 0.62 & 0.57 & 1.08 & 0.27 & 488 & 0.85 & 0.61 & 1.16 & 0.37 & 5531 \\
T_W (hour) & 0.64 & 0.69 & 1.12 & 0.54 & 488 & 0.85 & 0.85 & 1.15 & 0.80 & 5531 \\
N_O (chain) & 0.54 & 0.66 & 1.22 & 0.41 & 373 & 0.55 & 0.80 & 1.42 & 0.64 & 2915 \\
T_O (hour) & 0.39 & 0.57 & 0.88 & 0.54 & 373 & 0.44 & 0.77 & 1.14 & 0.86 & 2915 \\
\hline
\end{tabular}

TABLE 5: Goodness-of-fit of the two models.

\begin{tabular}{lcccccrr}
\hline Models & $\chi^{2}$ & DF & $P$ & $\chi^{2} / \mathrm{DF}$ & $\mathrm{RMSEA}^{1}$ & $\mathrm{GFI}^{2}$ & $\mathrm{CN}^{3}$ \\
\hline Model A & 79.8 & 88 & 0.722 & 0.907 & 0.000 & 0.991 & 1175 \\
Model B & 87.7 & 92 & 0.607 & 0.953 & 0.000 & 0.999 & 9912 \\
\hline
\end{tabular}

${ }^{1}$ RMSEA is root mean square error of approximation.

${ }^{2} \mathrm{GFI}$ is goodness-of-fit index.

${ }^{3} \mathrm{CN}$ is Hoelter's critical $N$.

household and individual characteristics not only influence trip chaining behavior directly, but also affect trip chaining indirectly through activity participation of individuals.

The above initial SEM models were estimated by using the software of AMOS 7.0. The maximum likelihood (ML) method was selected as the estimation method, because it converges more rapidly and the results are also easier to interpret compared with the "distribution free" approach (e.g., DWLS) [14]. Generally, the initial model does not perform well; thus, it needs some modification by adding or deleting links according to both their significance which is suggested by the model output and their interpretability. After the modification procedures, we obtained two final models, as shown in Figures 2 and 3.

Table 5 listed goodness-of-fit of the two models. For Model A, which represents the low-income group, the $\chi^{2}$ is 79.8 with 88 degrees of freedom, and $P$ value is 0.722 (greater than 0.05), indicating that the null hypothesis $\left(H_{0}: \Sigma=\right.$ $\boldsymbol{\Sigma}(\boldsymbol{\theta})$ ) cannot be rejected. Other measures of fit, such as GFI $=0.991$ (that ranges from 0 to 1 ), and root mean square error of approximation (RMSEA $=0.000$ ) are also found to be acceptable by model fit criteria for structural equation model. Hoelter's critical $N(\mathrm{CN})$ statistic is found to be 1175 (greater than 200 is considered a good fit), which is the sample size at which value of the fitting function $F_{\mathrm{ML}}$ would lead to the rejection of the null hypothesis, $H_{0}$ (i.e., $\boldsymbol{\Sigma}=\boldsymbol{\Sigma}(\boldsymbol{\theta})$ ), at a chosen significance level. Similarly, Model B, which is pertaining to the nonpoor, is also quite satisfactory.

\section{Model Estimation Results}

Tables 6-10 are the estimation results of Model A and Model B. There are three distinct types of relationships that can be obtained from structural equations modeling procedures.

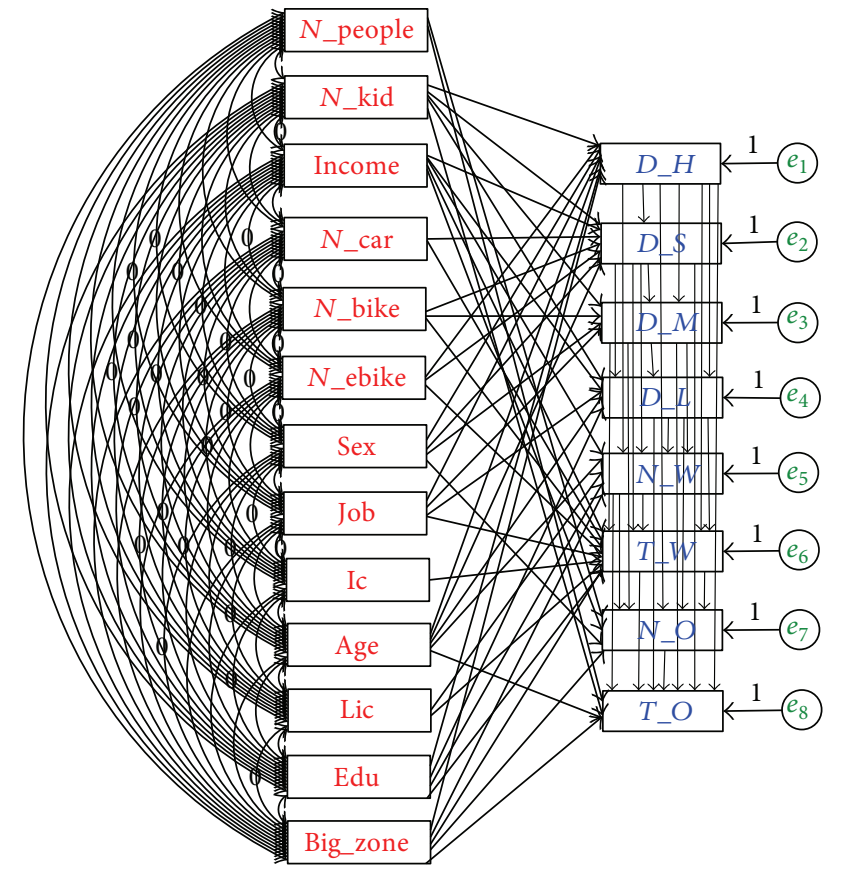

FIGURE 2: SEM path diagram for low-income group.

They are called direct effects, indirect effects, and total effects, respectively. Note that direct and indirect effects may be of different signs, thus having an important implication for the overall total effect. For example, it can be seen in Table 10 (Model A) that the subsistence activity duration $\left(D \_S\right)$ has a negative direct effect $(-0.121)$ and positive indirect effect (0.149) on the travel time of work chains $\left(T_{-} W\right)$. Because $D \_S$ has negative direct effects on $D \_M$ and $D \_L$ (e.g., -0.090 and -0.418 , resp.), both of which have negative direct effects 
TABLE 6: Total, direct, and indirect effects of sociodemographics on activity duration and trip chaining in Model A.

\begin{tabular}{|c|c|c|c|c|c|c|c|c|c|c|c|c|c|c|}
\hline & Effects & Big_Zone & $N_{\text {_people }}$ & $N$ _kid & Income & $N_{-}$car & $N \_$bike & N_Ebike & Sex & Job & IC & Age & Lic & Edu \\
\hline \multirow{3}{*}{$D H$} & Total & -0.833 & 0 & 0.504 & 0 & 0 & 0 & -0.372 & 1.245 & 0.257 & 0 & 0.554 & 0 & -1.342 \\
\hline & Direct & -0.883 & $\mathbf{0}$ & 0.504 & $\mathbf{0}$ & 0 & 0 & -0.372 & 1.245 & 0.257 & 0 & 0.554 & 0 & -1.342 \\
\hline & Indirect & 0 & 0 & 0 & 0 & 0 & 0 & 0 & 0 & 0 & 0 & 0 & 0 & 0 \\
\hline \multirow{3}{*}{$D \_S$} & Total & 0.747 & 0 & 0.030 & -0.270 & 0.620 & 0.245 & 0.731 & -1.354 & -0.217 & 0 & -0.922 & 0 & 1.136 \\
\hline & Direct & 0 & $\mathbf{0}$ & 0.457 & -0.270 & 0.620 & 0.245 & 0.416 & -0.300 & 0 & 0 & -0.453 & 0 & 0 \\
\hline & Indirect & 0.747 & 0 & -0.427 & 0 & 0 & 0 & 0.315 & -1.054 & -0.217 & 0 & -0.469 & 0 & 1.136 \\
\hline \multirow{3}{*}{$D \_M$} & Total & -0.049 & 0 & 0.084 & 0.024 & -0.056 & 0.055 & -0.058 & 0.305 & 0.037 & 0 & 0.072 & 0 & -0.075 \\
\hline & Direct & 0 & 0 & 0.097 & 0 & 0 & 0.077 & 0 & 0.209 & 0.023 & 0 & 0 & 0 & 0 \\
\hline & Indirect & -0.049 & 0 & -0.013 & 0.024 & -0.056 & -0.022 & -0.058 & 0.096 & 0.014 & 0 & -0.072 & 0 & -0.075 \\
\hline \multirow{3}{*}{$D \_L$} & Total & 0.003 & 0 & -0.143 & 0.045 & -0.216 & -0.144 & -0.144 & -0.060 & 0.033 & 0 & 0.229 & 0 & -0.197 \\
\hline & Direct & 0 & $\mathbf{0}$ & 0.093 & -0.050 & 0 & 0 & 0 & 0 & 0.051 & 0 & 0.073 & 0 & -0.202 \\
\hline & Indirect & 0.003 & 0 & -0.236 & 0.094 & -0216 & -0.144 & -0.144 & -0.060 & -0.018 & 0 & 0.156 & 0 & 0.005 \\
\hline \multirow{3}{*}{$N \_W$} & Total & 0.133 & 0 & -0.037 & 0.021 & 0.042 & 0.005 & 0.052 & -0.131 & -0.031 & 0 & -0.119 & -0.087 & 0.099 \\
\hline & Direct & 0.077 & 0 & 0 & 0.028 & 0 & 0 & 0 & 0 & 0 & 0 & -0.037 & -0.087 & -0.032 \\
\hline & Indirect & 0.056 & 0 & -0.037 & -0.007 & 0.042 & 0.005 & 0.052 & -0.131 & -0.031 & 0 & -0.082 & 0 & 0.131 \\
\hline \multirow{3}{*}{$T \_W$} & Total & 0.197 & 0 & -0.081 & 0.065 & -0.069 & -0.046 & 0.017 & -0.153 & -0.037 & -0.068 & -0.101 & 0.013 & 0.263 \\
\hline & Direct & 0.090 & 0 & 0 & 0.045 & -0.086 & -0.041 & -0.029 & 0 & 0.008 & -0.068 & 0 & 0.042 & 0.080 \\
\hline & Indirect & 0.107 & 0 & -0.081 & 0.020 & 0.017 & -0.005 & 0.045 & -0.153 & -0.045 & 0 & -0.101 & -0.029 & 0.184 \\
\hline \multirow{3}{*}{ N_O } & Total & -0.038 & 0.020 & 0.032 & 0.031 & -0.065 & -0.007 & -0.073 & 0.136 & 0.038 & 0.008 & 0.128 & 0.023 & -0.155 \\
\hline & Direct & 0.059 & 0.020 & 0 & 0.027 & 0 & o & 0 & -0.038 & 0 & 0 & 0 & 0 & 0 \\
\hline & Indirect & -0.097 & 0 & 0.032 & 0.004 & -0.065 & -0.007 & -0.073 & 0.174 & 0.038 & 0.008 & 0.128 & 0.023 & -0.155 \\
\hline \multirow{3}{*}{$T \_O$} & Total & -0.049 & -0.002 & -0.023 & 0.011 & -0.051 & -0.006 & -0.059 & 0.107 & 0.023 & 0.021 & 0.117 & 0.018 & -0.112 \\
\hline & Direct & 0.018 & -0.011 & -0.022 & $\mathbf{0}$ & 0 & 0 & 0 & 0 & 0 & 0 & 0.009 & 0 & 0 \\
\hline & Indirect & -0.067 & 0.009 & -0.001 & 0.011 & -0.051 & -0.006 & -0.059 & 0.107 & 0.023 & 0.021 & 0.108 & 0.018 & -0.112 \\
\hline
\end{tabular}

$(-0.312,-0.281)$ on $T_{-} W$. According to the effect analysis theory, the indirect effects of $D_{-} S$ on $T_{-} W$ can be computed as $(-0.090) \times(-0.312)+(-0.418) \times(-0.281)=0.149$. Therefore, the total effect (0.028) of $D_{-} S$ on $T_{-} W$ is the algebraic sum of direct effect $(-0.121)$ and indirect effect (0.149).

It is can be found that strong relationship exists among the sociodemographics, activity participation, and travel behavior, both for the poor and the nonpoor. In the following, we will examine the effects in detail from 4 aspects: effects of sociodemographics on activity duration and trip chaining, effects of activity durations on each other, effects of tripchaining on trip chaining, and effects of activity duration on trip chaining behavior.

6.1. Effects of Sociodemographics on Activity Duration and Trip Chaining. From Tables 6 and 7, we can see that, in both groups, some sociodemographics significantly affect all four types of activities and four trip chaining variables. The household and individual characteristics that are systematically important in explaining variations in activity participation and travel behavior include house location, income, number of preschool children, age, gender, and educational level.

Combining the path diagram in Figures 2 and 3, it can also be found that household characteristics have more influence on the activity participation of low-income population (12 routes from household characteristics to activity durations and 11 routes from individual characteristics to activity durations), while individual characteristics have more influence on the activity participation of the nonpoor ( 7 routes from household characteristics to activity durations and 17 routes from individual characteristics to activity durations). In addition, sociodemographics have more direct influence (22 routes) on the trip-chaining in the low-income group than that of the nonpoor (17 routes).

Specifically, the number of preschool children significantly affects the activity duration of the low-income group, but it has no effects on that of the non-low-income group. On the contrary, the IC factor does not influence low-income populations' activity duration at all but has significant effects on non-income populations.

6.2. Effects of Activity Duration on Activity Duration. From Table 8 , it can be found that interaction effects among 4 activity durations follow the same framework both in Model A and Model B. $D \_H$ has negative direct effects on the duration of out-of-home activities, $D \_M$ has negative effects on $D \_M$ and $D \_L$, and $D \_M$ has negative effects on $D \_L$.

However, the values of effects are not quite similar in the two models. For example, the absolute values of effects of $D \_H$ on other activity durations in Model A are all smaller than those in model $\mathrm{B}$, while the effects of $D \_M$ on $D \_L$ in Model A are larger than their counterparts in model $\mathrm{B}$, which indicates that the trade-off among the 4 type activities is differently in two groups. It can be interpreted that low-income population spend more time at home and have lower value of time due to their inferior social status and limited social network. 
TABLE 7: Total, direct, and indirect effects of sociodemographics on activity duration and trip chains in Model B.

\begin{tabular}{|c|c|c|c|c|c|c|c|c|c|c|c|c|c|c|}
\hline & Effects & Big_Zone & $N_{\text {_people }}$ & $N \_$kid & Income & $N_{-}$car & N_bike & $N$ Ebike & Sex & Job & IC & Age & Lic & Edu \\
\hline \multirow{3}{*}{$D \_H$} & Total & 0 & 0 & 0 & 0.103 & 0 & 0 & 0 & -1.158 & 0 & -0.285 & 0.19 & 0 & 0 \\
\hline & Direct & 0 & 0 & 0 & 0.103 & 0 & 0 & 0 & -1.158 & 0 & -0.285 & 0.19 & 0 & 0 \\
\hline & Indirect & 0 & 0 & 0 & 0 & 0 & 0 & 0 & 0 & 0 & 0 & 0 & 0 & 0 \\
\hline \multirow{3}{*}{$D \_S$} & Total & 0.424 & -0.119 & 0 & -0.273 & 0.159 & 0 & 0 & 1.365 & 0.054 & 0.547 & -0.189 & 0 & 0 \\
\hline & Direct & 0.424 & -0.119 & 0 & -0.171 & 0.159 & 0 & 0 & 0.213 & 0.054 & 0.263 & 0 & 0 & 0 \\
\hline & Indirect & 0 & 0 & 0 & -0.102 & 0 & 0 & 0 & 1.152 & 0 & 0.283 & -0.189 & 0 & 0 \\
\hline \multirow{3}{*}{$D \_M$} & Total & -0.009 & 0.017 & 0 & 0.093 & -0.022 & 0.017 & 0 & -0.247 & -0.029 & -0.067 & -0.003 & 0 & 0 \\
\hline & Direct & 0.05 & 0 & 0 & 0.058 & 0 & 0.017 & 0 & -0.097 & -0.021 & 0 & -0.023 & 0 & 0 \\
\hline & Indirect & -0.059 & 0.017 & 0 & 0.035 & -0.022 & 0 & 0 & -0.15 & -0.008 & -0.067 & 0.02 & 0 & 0 \\
\hline \multirow{3}{*}{$D \_L$} & Total & -0.201 & 0.096 & 0 & 0.149 & -0.068 & -0.007 & 0 & -0.226 & -0.053 & -0.131 & -0.016 & 0 & -0.13 \\
\hline & Direct & 0 & 0.045 & 0 & 0.092 & 0 & 0 & 0 & -0.097 & -0.038 & 0 & -0.038 & 0 & -0.13 \\
\hline & Indirect & -0.201 & 0.051 & 0 & 0.057 & -0.068 & -0.007 & 0 & -0.129 & -0.015 & -0.131 & 0.022 & 0 & 0 \\
\hline \multirow{3}{*}{$N \_W$} & Total & 0.127 & -0.018 & -0.031 & 0.012 & 0.026 & -0.003 & 0 & 0.138 & -0.005 & 0.078 & -0.016 & -0.031 & -0.016 \\
\hline & Direct & 0.105 & 0 & -0.031 & 0 & 0 & 0 & 0 & 0 & -0.021 & 0.038 & -0.014 & -0.031 & 0.035 \\
\hline & Indirect & 0.022 & -0.018 & 0 & 0.012 & 0.026 & -0.003 & 0 & 0.138 & 0.016 & 0.04 & -0.002 & 0 & -0.05 \\
\hline \multirow{3}{*}{$T \_W$} & Total & -0.044 & -0.019 & -0.009 & 0.002 & 0.049 & 0.005 & -0.008 & 0.243 & 0.014 & 0.059 & -0.014 & -0.009 & -0.037 \\
\hline & Direct & -0.069 & 0 & 0 & 0 & 0 & 0.009 & -0.008 & 0 & 0 & 0 & 0 & 0 & 0.02 \\
\hline & Indirect & 0.025 & -0.019 & -0.009 & 0.002 & 0.049 & -0.004 & 0 & 0.243 & 0.014 & 0.059 & -0.014 & -0.009 & -0.057 \\
\hline \multirow{3}{*}{ N_O } & Total & -0.052 & 0.034 & 0.005 & -0.027 & -0.039 & 0.005 & 0.007 & -0.217 & -0.024 & -0.081 & -0.01 & 0.005 & 0.096 \\
\hline & Direct & 0.019 & 0 & 0 & 0 & 0 & 0 & 0.006 & 0 & 0 & 0 & -0.014 & 0 & 0.017 \\
\hline & Indirect & -0.071 & 0.034 & 0.005 & -0.027 & -0.039 & 0.005 & 0 & -0.217 & -0.024 & -0.081 & 0.004 & 0.005 & 0.079 \\
\hline \multirow{3}{*}{ T_O } & Total & -0.099 & 0.034 & 0.007 & -0.03 & -0.033 & 0.002 & 0.006 & -0.259 & -0.02 & -0.084 & -0.005 & 0.007 & 0.077 \\
\hline & Direct & -0.036 & 0 & 0 & 0 & 0 & 0 & 0 & -0.069 & 0 & 0 & 0 & 0 & 0 \\
\hline & Indirect & -0.063 & 0.034 & 0.007 & -0.03 & -0.033 & 0.002 & 0.006 & -0.19 & -0.02 & -0.084 & -0.005 & 0.007 & 0.077 \\
\hline
\end{tabular}

TABLE 8: Total, direct, and indirect effects of activity duration on activity duration.

\begin{tabular}{|c|c|c|c|c|c|c|c|c|c|}
\hline & \multirow{2}{*}{ Effects } & \multicolumn{4}{|c|}{ Model A } & \multicolumn{4}{|c|}{ Model B } \\
\hline & & D_H & $D \_S$ & $D \_M$ & $D \_L$ & D_H & $D S S$ & $D \perp M$ & $D \_L$ \\
\hline \multirow{3}{*}{$D \_H$} & Total & 0 & 0 & 0 & 0 & 0 & 0 & 0 & 0 \\
\hline & Direct & 0 & 0 & 0 & 0 & 0 & 0 & 0 & 0 \\
\hline & Indirect & 0 & 0 & 0 & 0 & 0 & 0 & 0 & 0 \\
\hline \multirow{3}{*}{$D \_S$} & Total & -0.847 & 0 & 0 & 0 & -0.995 & 0 & 0 & 0 \\
\hline & Direct & -0.847 & 0 & 0 & 0 & -0.995 & 0 & 0 & 0 \\
\hline & Indirect & 0 & 0 & 0 & 0 & 0 & 0 & 0 & 0 \\
\hline \multirow{3}{*}{$D \_M$} & Total & 0.056 & -0.090 & 0 & 0 & 0.104 & -0.141 & 0 & 0 \\
\hline & Direct & -0.021 & -0.090 & 0 & 0 & -0.036 & -0.141 & 0 & 0 \\
\hline & Indirect & 0.076 & 0 & 0 & 0 & 0.140 & 0 & 0 & 0 \\
\hline \multirow{3}{*}{$D \perp$} & Total & -0.004 & -0.349 & -0.765 & 0 & 0.066 & -0.427 & -0.400 & 0 \\
\hline & Direct & -0.315 & -0.418 & -0.765 & 0 & -0.374 & -0.484 & -0.400 & 0 \\
\hline & Indirect & 0.311 & -0.069 & 0 & 0 & 0.440 & 0.056 & 0 & 0 \\
\hline
\end{tabular}

6.3. Effects of Trip Chaining on Trip Chaining. According to Table 9, the effects of trip-chaining characteristics on each other also follow similar frameworks in both models. Specifically, $N_{-} W$ has positive effects on $T_{-} W$ and negative effects on both $N_{-} O$ and $T_{-} O, T_{-} W$ has negative effects on $N_{-} O$ and $T_{-} O$, and $N_{-} O$ has negative effects on $T_{-} O$, which indicates that there are strong relationships and trade-offs between work chains and non-work chains.

Note that the absolute value of effects of work chains on non-work chains of the poor is larger than that of the nonpoor. It can be explained that low-income residents have less freedom to participate in different types of activities other than work due to their economic status.

6.4. Effects of Activity Duration on Trip Chaining. The estimation results in Table 10 show that, both for the poor and nonpoor, travel is derived from activity participation. Activity duration also affects trip chaining behavior besides sociodemographics. For example, we find that number of work chains $\left(N_{-} W\right)$ and the travel time of work chains $\left(T_{-} W\right)$ 
TABLE 9: Total, direct, and indirect effects of trip chaining on trip chaining.

\begin{tabular}{|c|c|c|c|c|c|c|c|c|c|}
\hline & \multirow{2}{*}{ Effects } & \multicolumn{4}{|c|}{ Model A } & \multicolumn{4}{|c|}{ Model B } \\
\hline & & $N_{-} W$ & $T_{-} W$ & N_O & T_O & $N \_W$ & $T_{-} W$ & N_O & T_O \\
\hline \multirow{3}{*}{$N_{-} W$} & Total & 0 & 0 & 0 & 0 & 0 & 0 & 0 & 0 \\
\hline & Direct & 0 & 0 & 0 & 0 & 0 & 0 & 0 & 0 \\
\hline & Indirect & 0 & 0 & 0 & 0 & 0 & 0 & 0 & 0 \\
\hline \multirow{3}{*}{$T_{-} W$} & Total & 0.334 & 0 & 0 & 0 & 0.308 & 0 & 0 & 0 \\
\hline & Direct & 0.334 & 0 & 0 & 0 & 0.308 & 0 & 0 & 0 \\
\hline & Indirect & 0 & 0 & 0 & 0 & 0 & 0 & 0 & 0 \\
\hline \multirow{3}{*}{ N_O } & Total & -0.318 & -0.113 & 0 & 0 & -0.167 & -0.056 & 0 & 0 \\
\hline & Direct & -0.281 & -0.113 & 0 & 0 & -0.150 & -0.056 & 0 & 0 \\
\hline & Indirect & -0.037 & 0 & 0 & 0 & -0.017 & 0 & 0 & 0 \\
\hline \multirow{3}{*}{$T \_O$} & Total & -0.349 & -0.302 & 0.433 & 0 & -0.237 & -0.274 & 0.600 & 0 \\
\hline & Direct & -0.127 & -0.253 & 0.433 & 0 & -0.063 & -0.241 & 0.600 & 0 \\
\hline & Indirect & -0.222 & -0.049 & 0 & 0 & -0.174 & -0.033 & 0 & 0 \\
\hline
\end{tabular}

TABLE 10: Total, direct, and indirect effects of activity duration on trip chaining.

\begin{tabular}{|c|c|c|c|c|c|c|c|c|c|}
\hline & \multirow{2}{*}{ Effects } & \multicolumn{4}{|c|}{ Model A } & \multicolumn{4}{|c|}{ Model B } \\
\hline & & $D H$ & $D \_S$ & $D \perp M$ & $D \_L$ & $D \_H$ & $D \_S$ & $D \_M$ & $D_{-} L$ \\
\hline \multirow{3}{*}{$N \_W$} & Total & -0.063 & 0.067 & -0.151 & -0.226 & -0.072 & 0.076 & -0.197 & -0.201 \\
\hline & Direct & -0.081 & -0.041 & -0.324 & -0.226 & -0.079 & -0.049 & -0.278 & -0.201 \\
\hline & Indirect & 0.018 & 0.108 & 0.173 & 0 & 0.007 & 0.125 & 0.081 & 0 \\
\hline \multirow{3}{*}{$T_{-} W$} & Total & -0.091 & 0.028 & -0.148 & -0.356 & -0.154 & 0.014 & -0.256 & -0.376 \\
\hline & Direct & -0.157 & -0.121 & -0.312 & -0.281 & -0.266 & -0.189 & -0.320 & -0.314 \\
\hline & Indirect & 0.065 & 0.149 & 0.164 & -0.076 & 0.111 & 0.203 & 0.064 & -0.062 \\
\hline \multirow{3}{*}{ N_O } & Total & 0.071 & -0.120 & 0.237 & 0.300 & 0.105 & -0.172 & 0.311 & 0.303 \\
\hline & Direct & 0.025 & 0 & 0.329 & 0.197 & 0.030 & 0 & 0.368 & 0.252 \\
\hline & Indirect & 0.046 & -0.120 & -0.091 & 0.103 & 0.075 & -0.172 & -0.057 & 0.051 \\
\hline \multirow{3}{*}{$T \_O$} & Total & 0.043 & -0.124 & 0.159 & 0.207 & 0.086 & -0.191 & 0.259 & 0.258 \\
\hline & Direct & -0.080 & -0.074 & -0.031 & -0.041 & -0.108 & -0.093 & -0.013 & -0.027 \\
\hline & Indirect & 0.123 & -0.050 & -0.191 & 0.249 & 0.194 & -0.098 & 0.272 & 0.285 \\
\hline
\end{tabular}

are directly affected by the 4 categories of activities. We also find that the $N_{-} W$ increases as the $D \_M$ or $D L$ decreases, while $N_{-} O$ increases as $D \_M$ or $D \_L$ increases.

From Table 10, we can also find that, in different models, the effects between the same variables are different. For example, the absolute value of total effect of $D \_M$ on $N_{-} W$ is smaller in the low-income group than in the non-low-income group; however, the corresponding absolute values of direct effect and indirect effect are larger in Model A than that in Model B.

In general, the absolute values of effects in Model B are greater than their counterparts in Model A, which indicates that activity participation has larger effects on the trip chaining characteristics in the group of non-low-income population than that of the poor. This scenario is possibly because the sample size of the low-income group (846) is much less than that of the non-low-income group (7534); thus, on the whole, the causal relationship of activity duration and trip chaining behavior revealed in Model B is stronger than that in Model A.

\section{Conclusions}

This paper focuses on the activity-trip chaining behavior of urban low-income populations in developing countries. Using the data of residents travel survey of Nanjing City (2009) and a specific travel survey of low-income residents of Nanjing City (2010), we proposes two structural equation models to investigate the relationships among sociodemographics, activity participation, and travel behavior of both low-income populations and non-low-income populations of Nanjing City. Based on the model outputs, we analyzed four categories of effects of the two groups. The general findings can be summarized as follows.

First, on average, the duration of out-of-home activities taken by the low-income populations is less than that of the non-low-income populations, and the less trip chains and less total travel time indicate that low-income populations generally do less out-of-home activities.

Second, the relationships among sociodemographics, activity duration, and trip chaining of both groups can be captured by the proposed SEM models, and most of the 


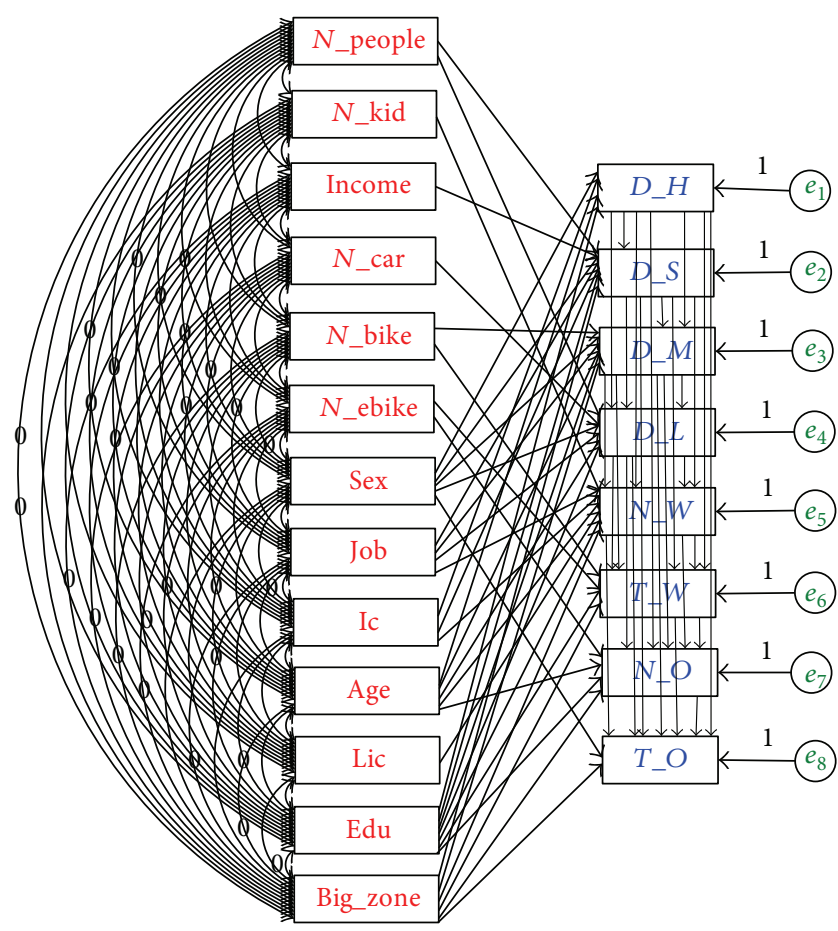

FIGURE 3: SEM path diagram for non-low-income group.

estimated effects are quite similar to those reported in the literature.

Third, both the structural equation models follow the same modeling framework. Therefore, the activity-trip chaining behavior of both the low-income populations and nonlow-income populations shares some similarities. For example, sociodemographics, especially household income; residential locations; age; and gender significantly affects the activity-trip chaining behavior of both the poor and the nonpoor.

Finally, low-income populations have some unique characteristics on the activity-travel behavior, which are different from those of the non-low-income populations. For instance, household characteristics have more influence on the activity participation of low-income population; the trade-off among the four type activities is differently in two groups; the effects of work chains on non-work chains of the poor are larger than those of the nonpoor; in general, activity participation has greater effects on trip chaining in the group of non-lowincome residents than that of low-income residents.

Based on these findings of travel behavior characteristics of urban low-income populations in developing countries, the following policies are suggested for the government and transportation agencies.

(1) Adopt transit-oriented transportation planning strategy, such as adding new shuttle buses from lowincome population concentrated areas to metro stations and opening new bus lines across low-income neighborhoods step by step.

(2) In order to reduce the monetary cost of low-income residents, the government can either subsidize them directly to improve social equity or introduce two or more bus operating companies to break the monopoly, so as to improve the level of bus service and reduce the bus fares.

(3) In the long-term planning, the city should transform from single center pattern to polycentric development pattern. Meanwhile, the government should consider hybrid land use and create more job opportunities near the residential area of low-income populations, such that low-income residents in the urban fringe will not waste two much time on their trip chains.

(4) Provide more vocational training for low-income adults and improve their ability of earning money. In addition, guarantee the next generation of lowincome residents can receive high quality education and help them climb higher along the social ladder. These policies can change their inferior position of travel fundamentally.

This research offers promising insights into the activitytravel behavior of the poor and extends the need to crafting effective transportation policies specifically for the urban low-income populations in developing countries. However, this research can be extended in terms of the following aspects: (a) conduct specific studies on the trading-off relationships between in-home and out-of-home activities; (b) study the interactions between activity participation and travel chaining behavior on two or more successive days; (c) consider the household level activity-travel behavior characteristics instead of individual level; (d) adopt the proposed SEM model to other cities in developing countries. It is hoped that these issues and others can be addressed in the future.

\section{Conflict of Interests}

The authors declare that there is no conflict of interests regarding the publication of this paper.

\section{Acknowledgments}

This research is supported by the National Natural Science Foundation of China (NSFC, no. 51078085, 51178109, 51178110, 51378119), Graduate Innovation Project of Jiangsu Province (No. CXZZ12_0113), and the Fundamental Research Funds for the Central Universities, China. The authors would like to express their appreciation towards Nanjing Institute of City \& Transport Planning Co., ltd., in particular, for the valuable assistance in obtaining and interpreting the data used for these models.

\section{References}

[1] G. Giuliano, H. Hu, and K. Lee, "The role of public transit in the mobility of low income households," Final Report, Metrans Transportation Center, Los Angeles, Calif, USA, 2001, http:// www.americandreamcoalition.org/automobility/transitforpoor.pdf.

[2] G. Giuliano, "Low income, public transit, and mobility," Transportation Research Record, no. 1927, pp. 63-70, 2005. 
[3] E. Blumenberg and P. Haas, "The travel behavior and needs of the poor: a study of welfare recipients in Fresno County," Publication FHWA-CA-OR-2001-23, FHWA, U.S. Department of Transportation, 2001.

[4] K. Clifton, "Examining travel choices of low-income populations-issues, methods, and new approaches," in Proceedings of the 10th International Conference on Travel Behavior Research, Lucerne, Switzerland, August 2003.

[5] N. McDonald, S. Librera, and E. Deakin, "Free transit for low-income youth: experience in San Francisco Bay area, California," Transportation Research Record, no. 1887, pp. 153160, 2004

[6] R. Behrens, "Understanding travel needs of the poor: Towards improved travel analysis practices in South Africa," Transport Reviews, vol. 24, no. 3, pp. 317-336, 2004.

[7] S. Srinivasan and P. Rogers, "Travel behavior of low-income residents: studying two contrasting locations in the city of Chennai, India," Journal of Transport Geography, vol. 13, no. 3, pp. 265-274, 2005.

[8] P. Thakuriah, P. S. Sriraj, S. Sööt, and Y. Liao, "Determinants of perceived importance of targeted transportation services for low-income riders," Transportation Research Record, no. 1986, pp. 145-153, 2006.

[9] J. Taylor, M. Barnard, H. Neil, and C. Creegan, The Travel Choices and Needs of Low Income Households: The Role of the Car, The National Centre for Social Research, London, UK, 2009, http://trid.trb.org/view.aspx?id=886473 .

[10] S. Gao and R. A. Johnston, "Public versus private mobility for low-income households: transit improvements versus increased car ownership in the sacramento, California, region," Transportation Research Record, no. 2125, pp. 9-15, 2009.

[11] T. F. Golob, "Structural equation modeling for travel behavior research," Transportation Research B: Methodological, vol. 37, no. 1, pp. 1-25, 2003.

[12] R. Kitamura, J. P. Robinson, T. F. Golob, M. A. Bradley, J. Leonard, and T. van der Hoorn, "A comparative analysis of time use data in the Netherlands and California," in Proceedings of the 20th PTRC Summer Annual Meeting: Transportation Planning Methods, pp. 127-138, 1992.

[13] X. Lu and E. I. Pas, "Socio-demographics, activity participation and travel behavior," Transportation Research A: Policy and Practice, vol. 33, no. 1, pp. 1-18, 1999.

[14] T. F. Golob, "A simultaneous model of household activity participation and trip chain generation," Transportation Research B: Methodological, vol. 34, no. 5, pp. 355-376, 2000.

[15] A. R. Kuppam and R. M. Pendyala, "A structural equations analysis of commuters' activity and travel patterns," Transportation, vol. 28, no. 1, pp. 33-54, 2001.

[16] J.-H. Chung and Y. Ahn, "Structural equation models of dayto-day activity participation and travel behavior in a developing country," Transportation Research Record, no. 1807, pp. 109-118, 2002.

[17] M. Yang, W. Wang, X. Chen, T. Wan, and R. Xu, "Empirical analysis of: commute trip chaining case study of Shangyu, China," Transportation Research Record, no. 2038, pp. 139-147, 2007.

[18] S. S. V. Subbarao and K. V. Krishna Rao, "Trip chaining behavior in developing countries: a study of Mumbai Metropolitan Region, India," European Transport, paper 3, no. 53, pp. 1-30, 2013.
[19] M. Yang, W. Wang, G. Ren, R. Fan, B. Qi, and X. Chen, "Structural equation model to analyze sociodemographics, activity participation, and trip chaining between household heads: survey of Shangyu, China," Transportation Research Record, no. 2157, pp. 38-45, 2010. 


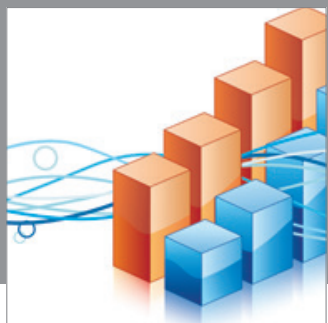

Advances in

Operations Research

mansans

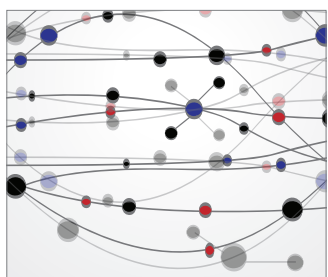

The Scientific World Journal
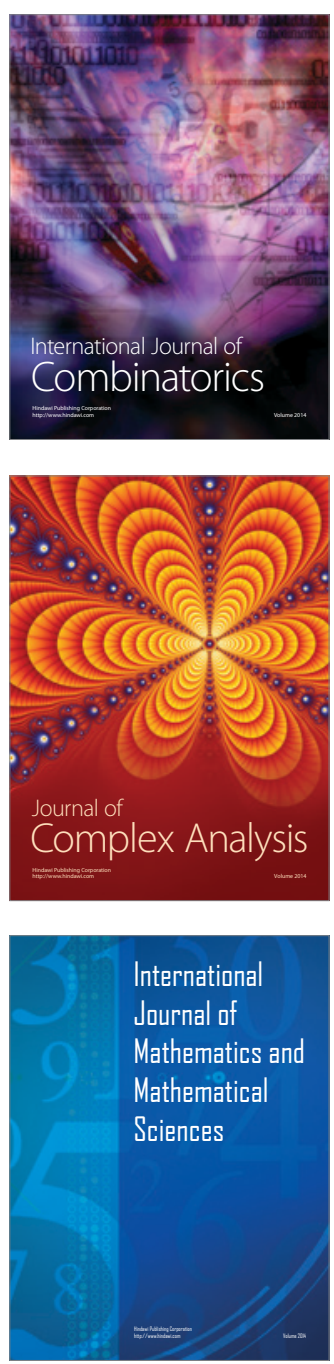
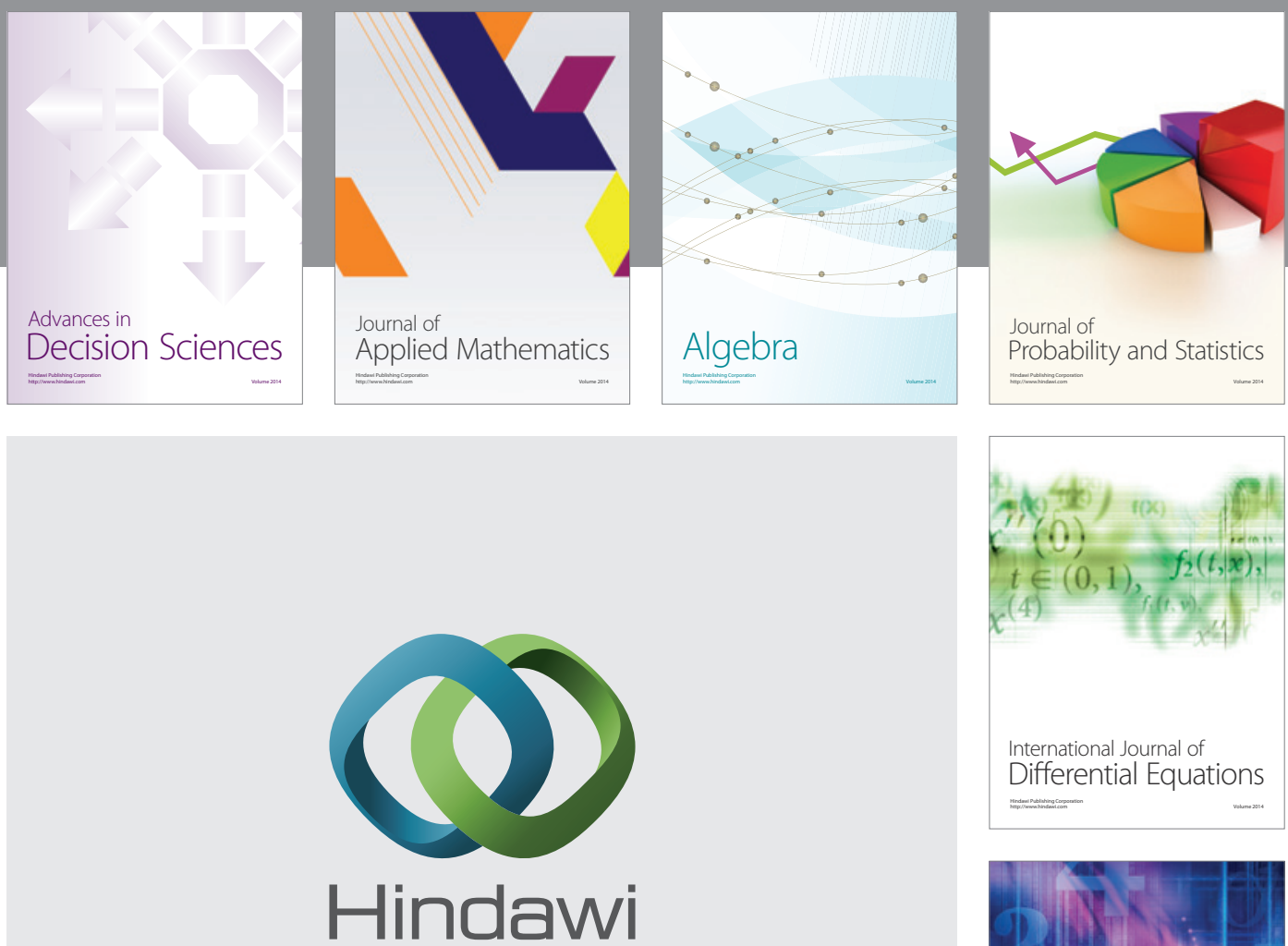

Submit your manuscripts at http://www.hindawi.com
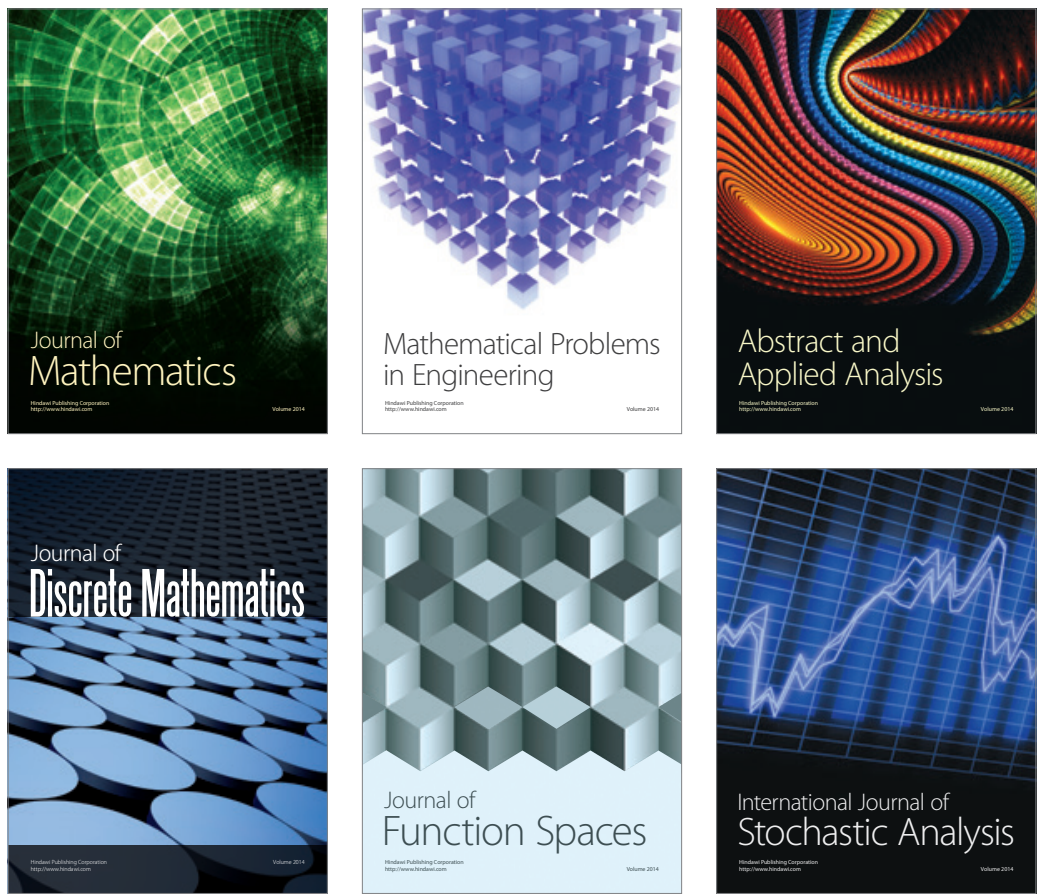

Journal of

Function Spaces

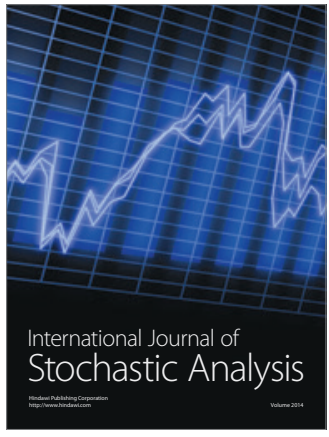

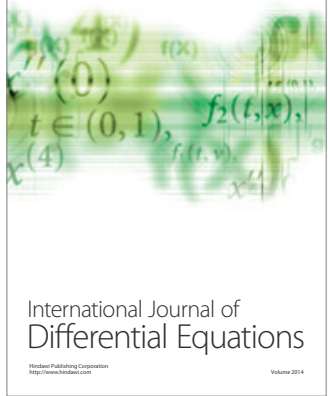
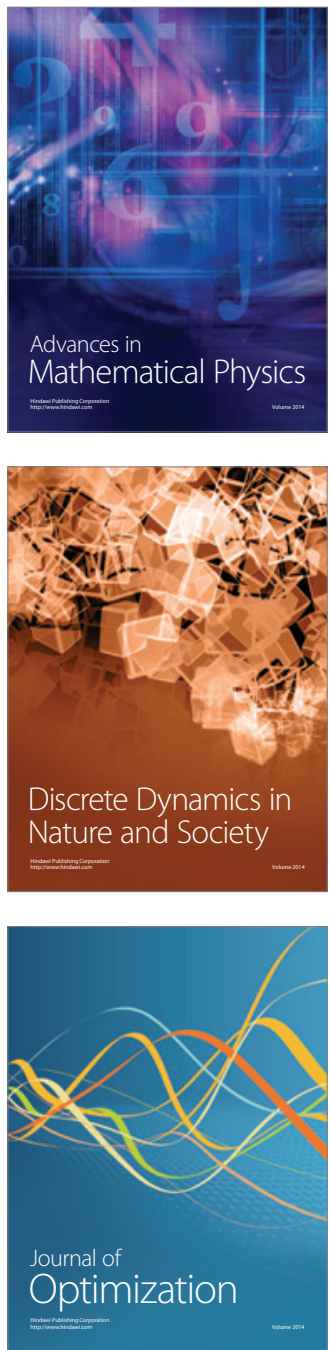